\title{
INVESTIGATION OF FRACTURE PROCESS OF S355JR STEEL IN TRANSITION REGION USING METALLOGRAPHIC AND FRACTOGRAPHIC TESTS AND NUMERICAL ANALYSIS
}

\author{
Ihor DZIOBA*, Sebastian LIPIEC ${ }^{*}$, Piotr FURMANCZYK**, Robert PALA \\ *Faculty of Mechatronics and Mechanical Engineering, Department of Machine Design, \\ Kielce University of Technology, Al. 1000-lecia PP 7, 25-314 Kielce, Poland \\ ${ }^{*}$ Faculty of Mechatronics and Mechanical Engineering, Department of Metal Science and Manufacturing Processes, \\ Kielce University of Technology, Al. 1000-lecia PP 7, 25-314 Kielce, Poland \\ pkmid@tu.kielce.pl, slipiec@tu.kielce.pl, pfurmanczyk@tu.kielce.pl, rpala@tu.kielce.pl
}

received 7 July 2017, revised 14 June 2018, accepted 19 June 2018

\begin{abstract}
In the paper are presented test results of fracture process in brittle-to-ductile transition range for two microstructural types of S355JR steel - ferrite-pearlite and ferrite-carbides. For both kinds of S355JR steel obtained in temperature range of transition region the strength and plastic properties are similar, but the fracture toughness characteristics showed significantly are various. To clarify the differences in the course of trends in the mechanical characteristics performed metallographic and fractographic observations using the scanning electronic microscope. The fractographic examination showed that changes in the fracture surface morphology were dependent on the test temperature. It was also found that during the subcritical crack growth the region of ductile fracture extension reduced with decreasing temperature. The results of finite element method (FEM) calculation the stress fields in front of the crack of single edge notch in bending (SENB) specimens in the range of brittle-to-ductile transition are presented also. The FEM calculations were performed on the numerical model of SENB specimen using the ABAQUS program.
\end{abstract}

Keywords: S355JR steel, Mechanical Properties, Microstructure, Fractographic Examination, Numerical Analysis, Stress Distributions

\section{INTRODUCTION}

The S355JR (18G2A) steel is a material widely used for different types of structural elements and systems. Its manufacturing process usually involves normalizing, which leads to the formation of a layered ferrite-pearlite (FP) or ferrite-pearlite-bainite microstructure (Dobrzański, 1999; Dzioba and Skrzypczyk, 2006; PN-EN 10025-2, 2007). When the steel is welded, its microstructure in the heat affected zone changes as a result of the formation of bainite or ferrite-bainite microstructures. Annealing or long-term exposure to elevated temperatures results in the spheroidization and coagulation of carbides, and, consequently, the formation of a microstructure ferrite with coarse carbide particles $(F C)$ in the ferrite or/and bainite regions as well as at the grain boundaries (Boumerzoug et al., 2010; Dymski et al., 2005). Changes to the microstructure, which are responsible for the changes in the strength and fracture toughness of the material, have a direct effect on the structure integrity. When the strength and reliability of a structure are assessed, it is important that the real characteristics of the material be taken into account (ASTM E1820-09, 2011; Chen and Cao, 2015; Dzioba and Neimtiz, 2007; FITNET, 2008). This analysis cannot base on the data contained in the material certificate.

Testing carried out under low temperature conditions is essential to assess the integrity of structures containing welded elements, especially when this temperature is from the range of ductile-to-brittle transition region and lower (Dymski et al., 2005). Assessment of structural integrity requires focusing on welded elements, because the mechanical properties of a material in the fusion and heat affected zones are much different from those of base metal (Dymski et al., 2005; Dzioba and Skrzypczyk, 2006).

Fractographic and metallographic investigations provide information on the mechanisms by which fracture occurs in steels and metallic alloys (Kocanda, 1978). The analysis of microstructure and fracture surfaces is necessary to identify the crack propagation behaviour and the internal factors affecting the failure process, such as dimension of the grains and types and size of inclusions or carbides.

According to the most important fracture criteria in order to realize the fracture process it is necessary to exceed the critical level of stress (or strain) on critical length (McClintok, 1968; Beremin, 1983; Rotchie et al., 1973; Seweryn, 1993; Seweryn and Mróz, 1995; Neimitz et al., 2007, 2010). So, the knowledge on local stress and/or strain distributions in the crack front is required. The components of stress and strain should be calculated using a numerical method.

\section{TEST METHODS, STRENGTH AND FRACTURE TOUGHNESS PROPERTIES, FRACTOGRAPHY OBSERVATION}

The two types of microstructure of S355JR steel were analyzed in present testing: ferrite-pearlite and ferrite with coagulated carbides. The FP microstructure (Fig. 1a) in the specimens was obtained as a result of normalization through annealing at $950^{\circ} \mathrm{C}$ per 20 minutes and cooling in the air. In the second heat treatment additionally to normalization carried out the annealing at 150 hours with cooling in oil, what leads to FC microstructure (Fig. 1b). 
The tests were conducted using a UTS/Zwick $(100 \mathrm{kN})$ testing machine with an electrodynamic drive and an automated control and data acquisition system. The strength properties of S355JR steel were determined through uniaxial tensile testing. Standard specimens of $5 \mathrm{~mm}$ in diameter were used for that purpose (PN-EN ISO 6892-1, 2010).

Because of the high plasticity of S355JR steel fracture toughness was determined as the critical value of J-integral, JIC, using single-edge notched specimens in three-point bending, SENB. The potential drop method or change compliance method were used to determine the critical values of fracture toughness for each single specimen tested. The specimens were prepared and tested in accordance with the ASTM standard (ASTM E1820-09, 2011).

The low-temperature tests were performed in the temperature range from $-130^{\circ} \mathrm{C}$ to $+20^{\circ} \mathrm{C}$ in a thermal chamber using liquid nitrogen as a coolant. A thermocouple was mounted directly on a specimen tested. During the measurements, the temperature changes did not exceed $\pm 1^{\circ} \mathrm{C}$; the measurement accuracy was $0.1^{\circ} \mathrm{C}$.

a)

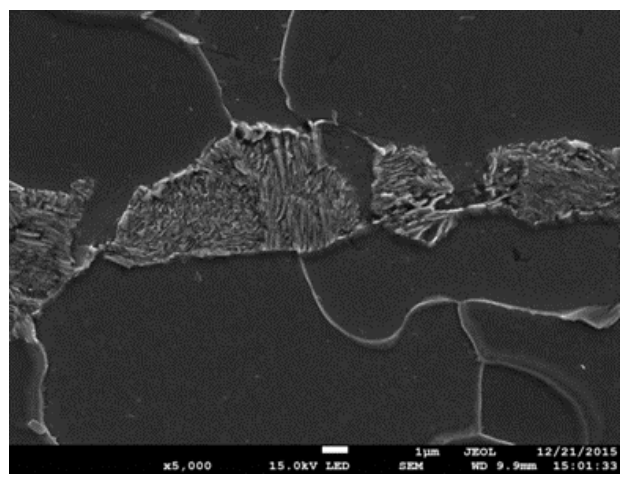

b)

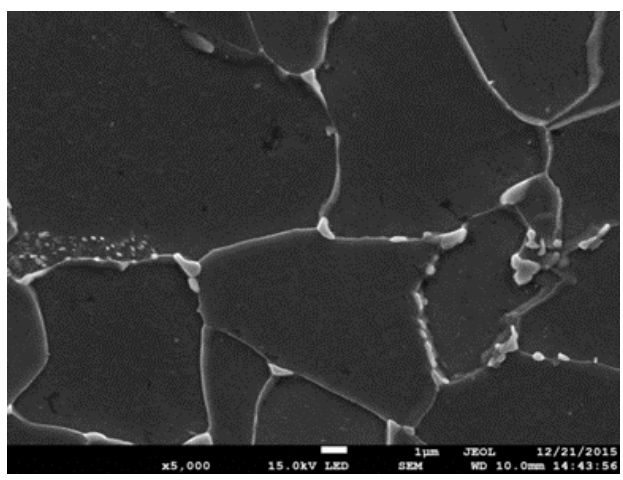

Fig. 1. The FP (a) and FC (b) microstructure types of S355JR steel

The true $\sigma-\varepsilon$ dependences were obtained in the range of testing temperature from data of tensile uniaxial test. The average data of strength characteristics of FP and FC microstructure of S355JR steel are presented in Tab. 1. Generally, the strength characteristics of FP material are some higher than of FC. For both kinds of S355JR steel microstructure, FP and FC, temperature lowering leads to increase in strength characteristics. Only the material hardening factor, $n$, slowly decreases with temperature reduction.

The process of sub-crack propagation in plasticity steel is realized in some stages. The initially sharp tip of pre-crack becomes blunted as a loading result. In certain moment the sub-crack starts. Fracture toughness according to this moment is denoted as $J_{i}$. The method for determining fracture toughness value in crack initiation moment was proposed in Japanese and ESIS (ESIS P2-92, 1992; JSME S 001-81, 1981) standards and in the paper by Zu-Han and Chang-Xiang (1985). According to these standards, $J_{i}$ is proportional to stretch zone width (SZW), $\Delta \bar{a}_{S Z W}$ : $J_{i}=\lambda \cdot \Delta \bar{a}_{\text {SZW }}$, which should measured using microscope. Factor $\lambda$ in various standards was differently defined. According to Shih (1981) proposal, $J_{i}$ is calculated from the equation:

$$
J_{i}=\frac{2 \sigma_{\mathrm{Y}}}{d_{\mathrm{n}}} \Delta \bar{a}_{\mathrm{SZW}}
$$

where: $\sigma_{Y}=0.5\left(\sigma_{Y S}+\sigma_{U T S}\right)$.

Tab.1. Mechanical properties of FP and FC microstructures of S355JR steel at test temperature range

\begin{tabular}{|c|c|c|c|c|c|}
\hline 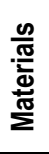 & Characteristics & $+20^{\circ} \mathrm{C}$ & $-50^{\circ} \mathrm{C}$ & $-80^{\circ} \mathrm{C}$ & $\begin{array}{c}-100^{\circ} \mathrm{C} \\
(\mathrm{FC}) / \\
-120^{\circ} \mathrm{C} \\
(\mathrm{FP})\end{array}$ \\
\hline \multirow{5}{*}{ FP } & $E[\mathrm{GPa}]$ & 202 & 210 & 212 & 214 \\
\hline & $\sigma \mathrm{LYS}[\mathrm{MPa}]$ & 378 & 414 & 414 & 473 \\
\hline & бuYs [MPa] & 380 & 428 & 456 & 522 \\
\hline & бUTs [MPa] & 613 & 670 & 673 & 686 \\
\hline & $n$ & 4.69 & 4.28 & 4.04 & 3.89 \\
\hline \multirow{5}{*}{ FC } & $E[\mathrm{GPa}]$ & 211 & 216 & 218 & 220 \\
\hline & $\sigma \mathrm{LYS}[\mathrm{MPa}]$ & 380 & 378 & 420 & 448 \\
\hline & ours [MPa] & 392 & 379 & 458 & 486 \\
\hline & бUts [MPa] & 588 & 626 & 626 & 681 \\
\hline & $n$ & 4.92 & 4.37 & 4.15 & 4.01 \\
\hline
\end{tabular}

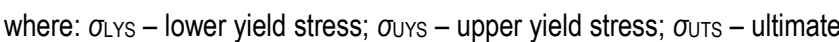
tensile strength.

a)

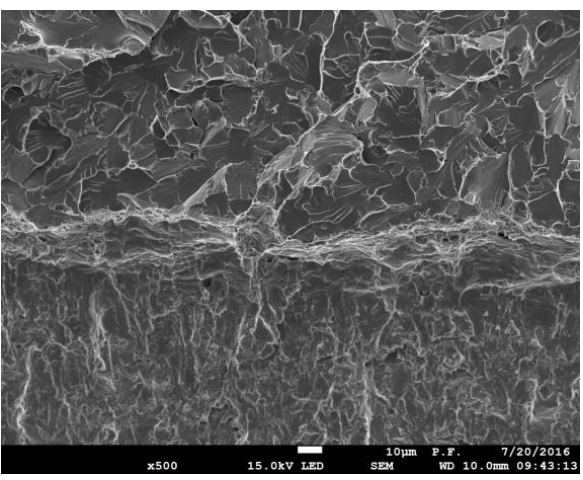

b)

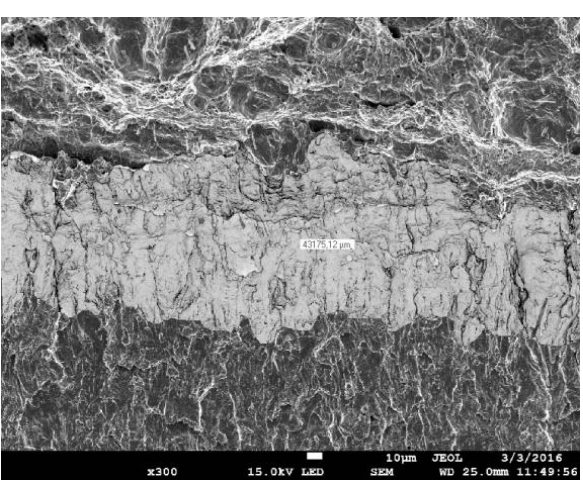

Fig. 2. The fracture surface of $F C$ material for: (a) $-80^{\circ} \mathrm{C}$; (b) $20^{\circ} \mathrm{C}$ with stretch zone area measured 
Coefficient $d_{\mathrm{n}}$ is a function dependency of power hardening factor $n$, and stress state in crack front. According to Guo (1995) proposal $\mathrm{d}_{\mathrm{n}}$ is function of $\mathrm{n}$ and stress state factor $T_{Z}$ :

$$
T_{Z}=\frac{\sigma_{33}}{\sigma_{11}+\sigma_{22}}
$$

In the current investigation the SZW were measured on fracture surfaces of SENB tested specimens using the scannig electronnic microscope (SEM) (Fig. 2a). The stretch zone area was measured (Fig. 2b). The average value of SZW was obtained by dividing area per length.

According to the ASTM standard (ASTM E1820-09, 2011) the fracture toughness critical value for sub-crack ductile propagation is determined for its extension equal to $0.2 \mathrm{~mm}$. So, it can be observed that there is some difference between fracture toughness measured at the initiation moment and for crack extension $0.2 \mathrm{~mm}$. This difference is significant for high plasticity material.

In Fig. 3 are shown curves, which present dependences of fracture toughness critical values on test temperature range. Three zones are present in each curve. The lower plateau, where crack extension is only by brittle cleavage fracture. The higher plateau, where crack growth is according to the ductile fracture mechanism. And the transition region, where growth cracks starts by ductile mechanism and mechanism of growth changes into brittle.

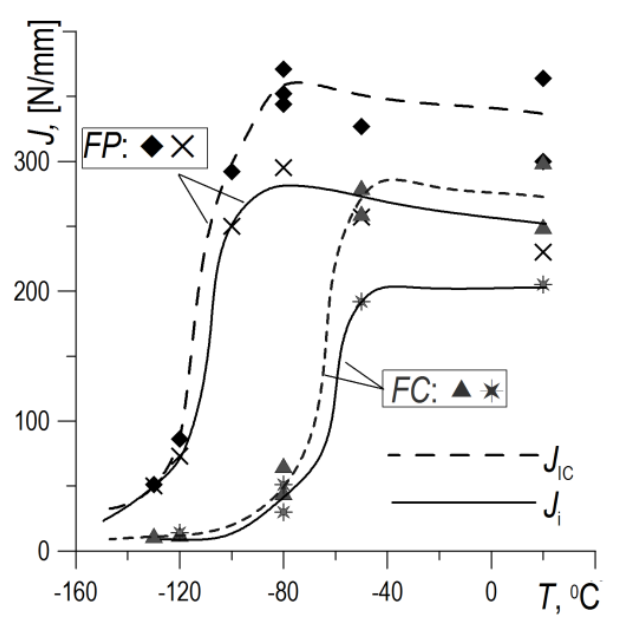

Fig. 3. The relations of fracture toughness critical values on temperature

The fracture toughness of FP material is higher than FC material. In the figure are presented data of fracture toughness $J_{I C}$ (dotted lines) and $J_{i}$ (solid lines) received at the crack initiation. The similar level of fracture toughness of $J_{\mathrm{IC}}$ and $J_{\mathrm{i}}$ are obtained only for full brittle fracture on the lower plateau. In the transition region and in the higher plateau, where is present ductile fracture, the value of $J_{\text {IC }}$ is higher. These differences increase together with temperature.

\section{NUMERICAL MODELING AND CALCULATION}

The FEM calculations were performed on the numerical model of SENB specimen ( $W=24 \mathrm{~mm}, S=96 \mathrm{~mm}, B=12 \mathrm{~mm})$ by using the ABAQUS program (Abaqus 6.12). In the first stage the true stress-strain relation was determined for the elasticplastic range. Nominal stress-strain data relation was used only to the max stress value, $\sigma_{\mathrm{UTS}}$. Using this data were calculated true stress and strain according to the well-known formulas (Boumerzoug et al., 2010; Chen et al., 2015):

$$
\begin{aligned}
\epsilon_{t} & =\ln \left(1+\epsilon_{\text {nom }}\right) \\
\sigma_{t} & =\sigma_{\text {nom }}\left(1+\epsilon_{\text {nom }}\right)
\end{aligned}
$$

where: $\epsilon_{\mathrm{t}}-$ true strain, $\sigma_{\mathrm{t}}-$ true stress, $\varepsilon_{\text {nom }}-$ nominal strain, $\sigma_{\text {nom }}-$ nominal stress.

From the linear part of the stress-strain relation was determined the Young modulus. The non-linear part of the stress-strain relation was interpolated in the direction of the increased stress values by the linear function approximation of $100-120$ last points from the data set (Neimitz and Galkiewicz, 2010). The true plastic components of strain were obtained by using the formula:

$\varepsilon_{p l}=\varepsilon_{t}-\frac{\sigma_{t}}{E}$

The SENB specimen was divided into 12 layers in thickness direction. The 8 nodes three-dimensional elements were used in calculation. Density of the elements mesh increases in the direction to crack tip. The crack tip was modelled as an arc of 0.012 $\mathrm{mm}$ in the radius.

The possibility of transference was blocked according to the scheme shown in Fig. 4. The process of load simulation was generated by moving the high pin roller in $y$ axis direction. The roller position was taken from the experimental load-displacement record.

a)

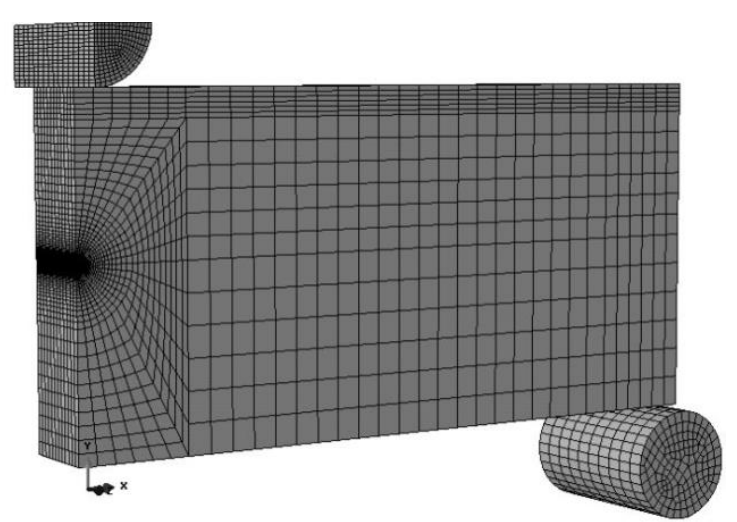

b)

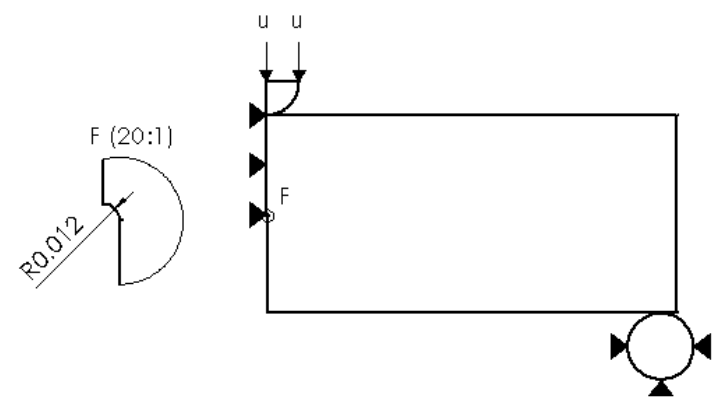

Fig. 4. The three points bend (SENB) specimen model: a) numerical model with mesh, b) boundary conditions scheme

In numerical calculation C3D8R finite elements were used. The three-dimensional problem using 8-nodes elements was solved numerically. Three-point bending specimen model contained 21600 elements. The finite elements size was reduced from furthest areas, to the crack front. In the area immediate at top crack the dimension of elements was equal to about $0.02 \mathrm{~mm}$. 
While on the furthest areas the elements dimension was equal to about $1.6 \mathrm{~mm}$ (Fig. 8a). Finite element mesh quality in a model was compromised using the Abaqus grid quality option.

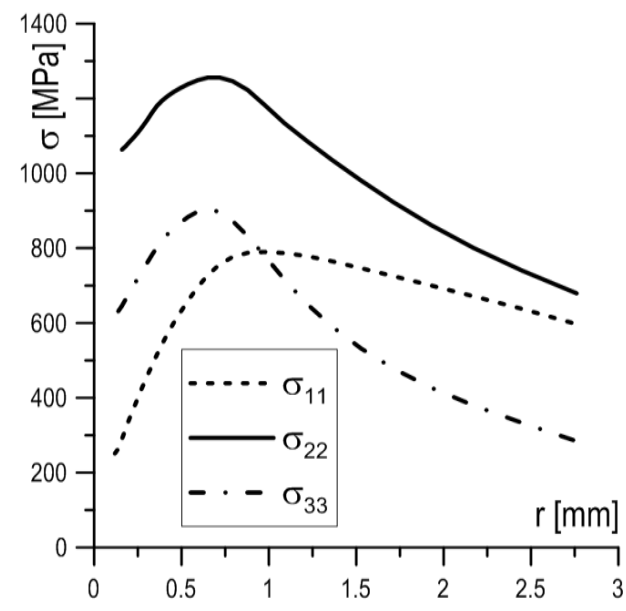

Fig. 5. The distributions of stress components in the axis plane of specimen, $\mathrm{FC}$ material, $T_{\text {test }}=+20^{\circ} \mathrm{C}$

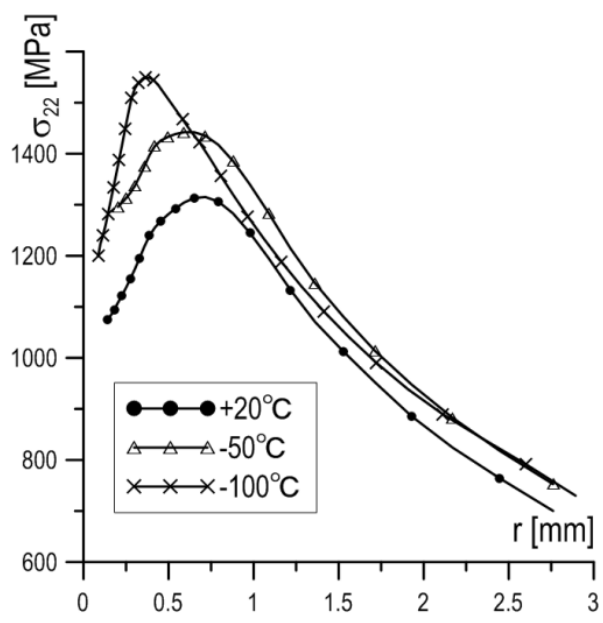

Fig. 6. The opening stresses distributions $\sigma_{22}$ in the axis plane of specimen, $\mathrm{FP}$ material, $T_{\text {test }}=+20^{\circ} \mathrm{C},-50^{\circ} \mathrm{C}$ and $-100^{\circ} \mathrm{C}$

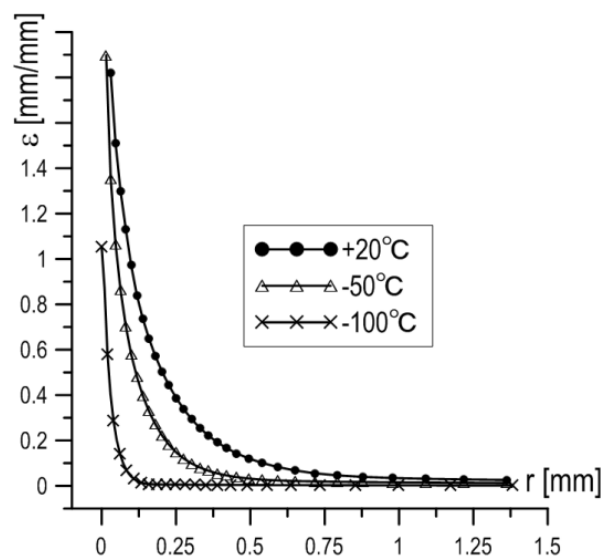

Fig. 7. The equivalent strain distributions in the axis plane of specimen, FC material, $T_{\text {test }}=+20^{\circ} \mathrm{C},-50^{\circ} \mathrm{C}$ and $-100^{\circ} \mathrm{C}$

The stress and strain distributions in the crack front were obtained. For example in Fig. 5 presented the components of stress distribution: $\sigma_{11}-$ in direction of crack growth; $\sigma_{22}$ - normal to crack plane; $\sigma_{33}$ - in direction of specimen thickness. The examples of changes the distributions stress and strain components of temperature influence are shown in Figs 6, 7.

\section{RESULTS AND DISCUSION}

The stress state factors $T_{\mathrm{Z}}$ and $R_{\text {eff }}$ were calculated based on the stress distributions in front of the crack. Stress state factor $T_{Z}$ was defined above. This quantity is needful for calculation of $d_{n}$ and secondly $J_{i}$. Stress state factor $R_{\text {eff }}$ was defined by Rice and Tracey (1969):

$$
\begin{aligned}
& R_{\text {eff }}=\frac{\left(\sigma_{11}+\sigma_{22}+\sigma_{33}\right) / 3}{\sigma_{\text {eff }}} \\
& \sigma_{\text {eff }} \\
& =\frac{1}{\sqrt{2}} \sqrt{\left(\sigma_{11}-\sigma_{22}\right)^{2}+\left(\sigma_{22}-\sigma_{33}\right)^{2}+\left(\sigma_{11}-\sigma_{33}\right)^{2}}
\end{aligned}
$$

Stress state factor $R_{\text {eff }}$ is used to characterize the material tendency to brittle or ductile fracture. High level of $R_{\text {eff }}$ identifies with material tendencies to brittle fracture, while when shown low level of $R_{\text {eff }}$ the fracture is realized according to ductile mechanism. The distributions of $R_{\text {eff }}$ levels in thickness direction of SENB specimens are shown in Fig. 8. The maximum level of $R_{\text {eff }}$ is observed in the middle part of specimen thickness. In the direction to specimen side the level of $R_{\text {eff }}$ decreases. The $R_{\text {eff }}$ distributions in thickness direction of FP microstructure are presented in Fig. 8a. For the specimens tested at temperature range from $20^{\circ} \mathrm{C}$ to $-80^{\circ} \mathrm{C}$, in which sub-critical crack grows according to brittle mechanism, level of $R_{\text {eff }}$ is a similar - max values about 2.2 in central plane and $1.6 \div 1.7$ in the side plane of the specimen. Significant increasing of the $R_{\text {eff }}$ level takes place if brittle cleavage extension of sub-critical crack occurred, as for specimen tested at $-120^{\circ} \mathrm{C}$.

The data of $R_{\text {eff }}$ distributions with thickness of FC microstructure specimens are shown in Fig. 8b. Full ductile mechanism of sub-critical crack growth in the specimens of FC material was noticed only at $20^{\circ} \mathrm{C}$. The $R_{\text {eff }}$ distribution for this specimen placed lowermost. At test temperature $-50^{\circ} \mathrm{C}$ sub-critical crack starts by ductile, and after some crack extension takes place change of growth mechanism by cleavage. The $R_{\text {eff }}$ distribution for this specimen is located some higher than the previous one. The brittle cleavage mechanism was realized at cracks extension for test temperature lower than $-80^{\circ} \mathrm{C}$. The dependences for specimens tested at $-80^{\circ} \mathrm{C}$ and $-100^{\circ} \mathrm{C}$ are put close one by one. The maximum level of $R_{\text {eff }}$ factor reaches to about 2.5 in the middle part of the specimens and to about $2.0 \div 2.1$ in the side plane of the specimen.

In Fig. 9 are shown the dependences of $R_{\text {eff }}$ average values and fracture toughness $J_{i}$ values with temperature for FP and FC microstructure of S355JR steel. The mean values of the $R_{\text {eff }}$ were calculated as the arithmetic mean of the stress state factor values along the specimen thickness, based on the data in Fig. 8. The average values of $R_{\text {eff }}$ keep some stable level for ductile sub-crack growth in the zone where $J_{i}$ belongs to the higher plateau. The $R_{\text {eff }}$ level increases with test temperature lowering in the transition region of $J_{i}$ data, when cleavage cracking is present.

For both types of S355JR steel, the level of strength properties oYs, oUTs, $E$ increase, while hardening factor $n$ decreases, 
with temperature lowering. The level for all strength characteristics of FP microstructure is some higher compared to FC.

a)

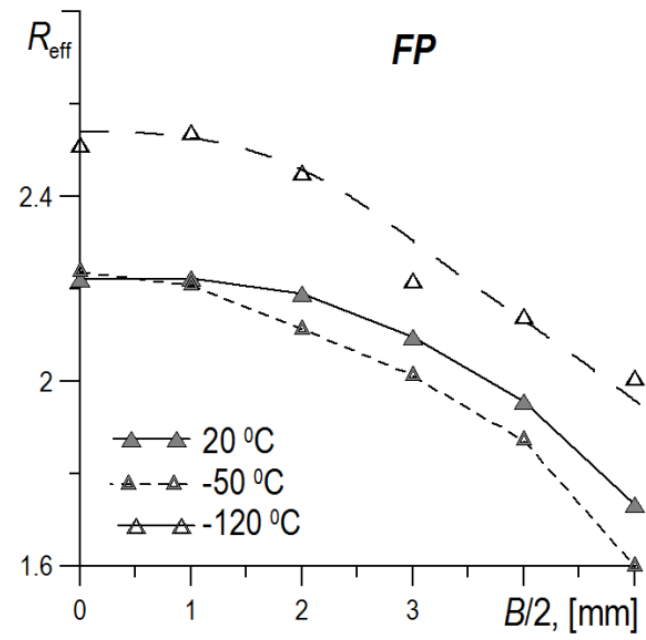

b)

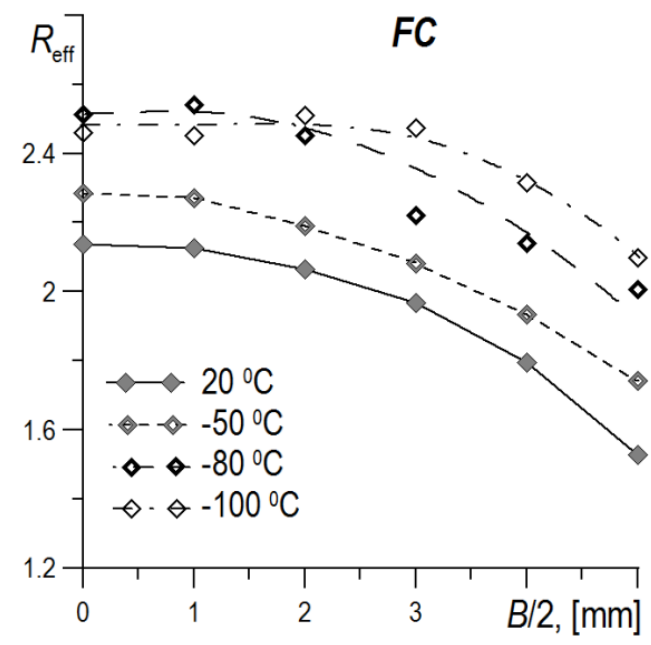

Fig. 8. The $R_{\text {eff }}$ distributions in thickness direction of FP (a) and FC (b) material for test temperatures

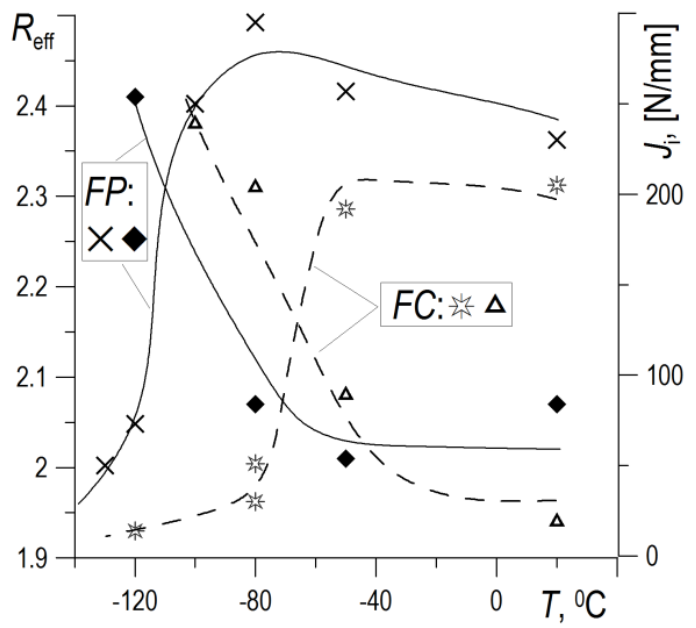

Fig. 9. Relationships between $R$ eff average values, $\mathrm{Ji}$ and test temperature
The critical values of fracture toughness of S355JR steel with FP microstructure are higher than of FC in tested temperature interval. The fracture toughness in initiation moment $J_{i}$ was determined by using results scanning microscope tests of fracture surfaces and numerical calculation of stress components in crack front of the tested specimens. The fracture toughness levels $\mathrm{J}_{\mathrm{i}}$ are similar to $J_{I C}$ only for full cleavage mechanism cracking. However, if ductile crack extension is present, $J_{\mathrm{IC}}$ is higher than $\mathrm{J}_{\mathrm{i}}$.

FEM calculation of SENB specimens allows to obtain stress and strain distributions in front of the crack. The stress state factors $T_{z}$ and $R_{\text {eff }}$ in front of the crack were calculated also.

It was shown that fracture mechanism strictly depends on stress state factor $R_{\text {eff. }}$ For both types of microstructure, FP and FC, cleavage cracking takes place when the average value of $R_{\text {eff }}$ in specimen exceeds the level of 2.1. When the average level of $R_{\text {eff }}$ was lower than 2.0 the ductile mechanism of crack extension occurred in the specimens. For specimens in which were observed ductile mechanisms of sub-crack extension, also performed high level of strain in front of the crack (Fig. 7). The high level of strain in front of the crack exactly leads to growth of cavity around particles of carbides and inclusion.

\section{REFERENCES}

1. Abaqus 6.12. Getting Started with Abaqus, Interactive Edition.

2. Anderson T.L. (2008), Fracture Mechanics, Taylor and Francis Group.

3. ASTM E1820-09. (2011), Standard Test Method for Measurement of Fracture Toughness. Annual Book of ASTM Standards, 03.01, 1070-1118.

4. Beremin F.M. (1983), A local criterion for cleavage fracture of a nuclear pressure vessel steel, Metallurgical Transaction A, 14A, 2277-2287.

5. Boumerzoug Z., Derfouf Ch., Baudin T. (2010), Effect of welding on microstructure and mechanical properties of an industrial low carbon steel, Scientific Research Engineering, 2, 502-506.

6. Chen J.H., Cao R. (2015), Micromechanism of cleavage fracture of metals, Elsevier.

7. Dobrzanski L.A. (1999), Materials science lexicon, basic settlement of Polish, foreign and international standard, Metals, Polymers, Ceramics, Composites, Verlag Dshofer (in Polish).

8. Dymski S., Gietka T., Stawicka Z., Kaczmarek M. (2005), Testing of influence low temperaturę on cracking a welded joint, Welded Review, 4, 99-106 (in Polish).

9. Dzioba I., Neimitz A. (2007), Application of the standard options of the FITNET Procedure to the structural integrity assessment of welded specimens containing cracks, International Journal of Pressure Vessels and Piping, 84(8), 475-486.

10. Dzioba I., Skrzypczyk A. (2006), Properties and microstructure of MAG but-welded joints of 18G2A steel, Welded Review, 9-10, 32-35 (in Polish).

11. Dzioba I., Neimitz A., Gajewski M. (2010), Studies of fracture process in $\mathrm{Cr}-\mathrm{Mo}-\mathrm{V}$ ferritic steel with various types of microstructure, International Journal of Pressure Vessels and Piping, 87, 575-586.

12. ESIS P2-92. (1992), Procedure for Determining the Fracture Behaviour of Materials, Appendix 4. A4.1-A4.6.

13. FITNET. Fitness for service. Fracture fatigue creep corrosion (2008), In: Kocak M., Webster S., Janosch J.J., Ainsworth R.A., Koers R., editor. GKSS Research Centre, Geesthacht.

14. Guo W.L. (1995), Elastoplastic three dimensional crack border field III. Fracture parameters, Engineering Fracture Mechanics, 51, 51-71.

15. JSME S 001-81. (1981), Standard Method of Test for Elastic-Plastic Fracture Toughness $J_{I C}$. JSME Standard, Japan.

16. Kocanda S. (1978), Fatigue Destruction of Metals, WNT (in Polish). 
17. McClintok F.A. (1968), Criterion for ductile fracture by growth of holes, Journal of Applied Mechanics, 35, 363-371.

18. Neimitz A., Galkiewicz J. (2010), Aproximation of stress-strain curve in front of a crack in a non-linear material, International Journal of Fracture, 161(1), 227-232.

19. Neimitz A., Graba M., Galkiewicz J. (2007), An alternative formulation of Ritchie-Knott-Rice local fracture criterion, Engineering Fracture Mechanics, 74, 1308-1322.

20. PN-EN 10025-2:2007: Hot Rolled Products of Structural Steels. Part 2. Technical Delivery Conditions for Non-alloy Structural Steels (in Polish).

21. PN-EN ISO 6892-1:2010. Metallic Materials. Tensile Testing. Part 1. Method of Test at Room Temperature (in Polish).

22. Rice J.R., Tacey, D.M. (1969), On the ductile enlargement of voids in triaxial stress fields, Journal of the Mechanics and Physics of Solids, 17, 201-217.

23. Ritchie R.O., Knott J.F., Rice J.R. (1973), On the relationship between critical tensile stress and fracture toughness in mild steel, Journal of the Mechanics and Physics of Solids, 21, 395-410.

24. Seweryn A. (1993), Brittle fracture criterion for structures with sharp notches, Engineering Fracture Mechanics, 45, 673-681.

25. Seweryn A., Mroz Z. (1995), A non-local stress and strain energy release rate mixed mode fracture initiation and propagation criteria. Engineering Fracture Mechanics, 51, 955-973.

26. Shih C.F. (1981), Relationship between the J-integral and crack opening displacement for stationary and extending crack, Journal of the Mechanics and Physics of Solids, 29, 305-329.

27. Zu-Han L., Chang-Xiang M. (1985), Comparison of several methods of $J_{I C}$ determination, Engineering Fracture Mechanics, 22, $1117-1119$.

Acknowledgment: The research testing was supported by the National Science Centre of Poland (No. 2014/15/B/ST8/00205) and the Ministry of Science and Higher Education of Poland

(No. 01.0.08.00/2.01.01.01.0008). 